\title{
Forced expiratory manoeuvres in children: do they meet ATS and ERS criteria for spirometry?
}

\author{
H.G.M. Arets, H.J.L. Brackel, C.K. van der Ent
}

Forced expiratory manoeuvres in children: do they meet ATS and ERS criteria for spirometry? H.G.M. Arets, H.J.L. Brackel, C.K. van der Ent. (C)ERS Journals Ltd 2001.

ABSTRACT: The aim of this study was to evaluate the applicability of American Thoracic Society and European Respiratory Society criteria for spirometry in children.

Maximal expiratory flow/volume (MEFV) measurements from 446 school-age children, experienced in performing MEFV manoeuvres, were studied and acceptability (start-of-test (backward extrapolated volume as a percentage of forced vital capacity $(\mathrm{FVC})\left(V_{\mathrm{be}} \% \mathrm{FVC}\right)$ or as an absolute value $\left(V_{\mathrm{be}}\right)$, end-of-test (forced expiratory time (FET)) and reproducibility criteria (absolute and percentage difference between best and second-best FVC and forced expiratory volume in one second (FEV1) ( $\triangle F V C$, $\triangle F V C \%, \triangle F E V 1$ and $\triangle F E V 1 \%)$ ) were applied to these manoeuvres.

The $V_{\text {be }} \% \mathrm{FVC}$ criterion was met by $91.5 \%$, the $V_{\text {be }}<0.15 \mathrm{~L}$ criterion by $94.8 \%$ and the $V$ be $<0.10 \mathrm{~L}$ by $60.1 \%$ of children. $V$ be $<0.15 \mathrm{~L}$ appeared to be a more useful parameter than $V_{b e} \%$ FVC. The FET criterion was met by only $15.3 \%$ of children. $\triangle F V C<0.2 \mathrm{~L}$ and $\triangle F E V 1<0.2 \mathrm{~L}$ were met by $97.1 \%$ and $98.4 \%$, and $\triangle F V C<0.1 \mathrm{~L}$ and $\triangle F E V 1<0.1 \mathrm{~L}$ by $79.8 \%$ and $84.3 \%$ of the children, respectively. These criteria appeared to be less useful compared to percentage criteria ( $\triangle F V C \%$ and $\triangle F E V 1 \%)$. Even experienced children did not meet all international criteria for spirometry. However, most of their MEFV curves are useful for interpretation.

Based on the performance of these children, a re-evaluation of criteria for maximal expiratory flow/volume measurements in children is proposed.

Eur Respir J 2001; 18: 655-660.
Dept of Paediatric Pulmonology, University Medical Centre Utrecht, Utrecht, the Netherlands.

Correspondence: H.G.M. Arets, Dept of Paediatric Pulmonology, KG01.319.0, University Medical Centre Utrecht, P.O. Box 85090, 3508 AB Utrecht, the Netherlands.

Fax: 31302505347

Keywords: American Thoracic Society criteria

children

European Respiratory Society criteria maximal expiratory flow/volume curves spirometry

Received: January 102001

Accepted after revision May 252001
Maximal expiratory flow/volume (MEFV) measurements were introduced as a valuable tool in the assessment of respiratory disease in 1947 [1]. Since then, MEFV measurement has become the cornerstone of pulmonary function testing (PFT) as well as the most widely used tool in diagnosis and follow-up of both adults and children with respiratory illness.

However, for young children, the technique of MEFV measurement is often complicated, because they may lack coordination and cooperation. For these children, especially those under the age of $7 \mathrm{yrs}$, the instruction and performance of MEFV manoeuvres can be facilitated by the use of computerized visual incentives [2]. In everyday practice, MEFV curves are judged to be acceptable when they show a rapid rise to peak flow at the start and a subsequent gradual decrease of flow during the rest of the maximally prolonged expiratory manoeuvre. However, criteria as described by the American Thoracic Society (ATS) [3] and European Respiratory Society (ERS) [4] for acceptability and reproducibility of MEFV manoeuvres, are lacking for (young) children. A summary of these criteria is shown in table 1 . In daily practice, when children perform computer-controlled MEFV manoeuvres, the ATS or ERS criteria will usually be indicated as not having been reached.

The aim of the investigation was to discover whether children with experience in lung function testing meet acceptability and reproducibility criteria for MEFV manoeuvres as defined by the ATS and ERS, during routine PFT. For criteria that were not met by these children, new criteria are proposed.

\section{Patients and methods}

All MEFV measurements were performed using a pneumotachometer system with a heated Lilly head (MasterScreen Pneumo and Jaeger Masterlab, Erich Jaeger, Würzburg, Germany). The calibration of equipment conformed to European Community for Steel and Coal guidelines [4]. All measurements were body temperature, pressure and saturation corrected. Measurements were performed with the child sitting straight and wearing a noseclip. Only prebronchodilator manoeuvres were evaluated.

Most patients were known to have recurrent respiratory symptoms, mostly due to obstructive pulmonary diseases, such as asthma and cystic fibrosis, or recurrent pulmonary infections. A minority of patients were seen preoperatively (e.g. for scoliosis, pectus excavatum) or after chemotherapy.

In the period January 1997-January 1999, 852 children (436 males) performed 8,388 MEFV tests at 
Table 1.-Criteria for acceptability and reproducibility of maximal expiratory flow/volume curves as stated by the American Thoracic Society (ATS) [3] and European Respiratory Society (ERS) [4]

\section{Acceptability}

Start-of-test criteria

$V$ be $\% \mathrm{FVC}<5 \%$ or $V$ be $<0.15 \mathrm{~L}$, whichever is greater (ATS)

$V$ be $\% \mathrm{FVC}<5 \%$ or $V$ be $<0.10 \mathrm{~L}$, whichever is greater (ERS)

End-of-test criteria

FET $>6$ (ATS)

Exhaustion of patient or plateau in time/volume curve (no volume change during $1 \mathrm{~s}$ ) (ATS and ERS)

No coughing, Valsalva manoeuvre or hesitation (ATS and ERS)

\section{Reproducibility}

$\Delta \mathrm{FVC}<200 \mathrm{~mL}$ and $\triangle \mathrm{FEV} 1<200 \mathrm{~mL}$ (ATS)

$\Delta \mathrm{FVC} \%<5 \%$ or $\Delta \mathrm{FVC}<100 \mathrm{~mL}$, whichever is greater and $\Delta \mathrm{FEV} 1 \%<5 \%$ or $\Delta \mathrm{FEV} 1 \%<100 \mathrm{~mL}$, whichever is greater (ERS)

$V$ be $\%$ FVC: backward extrapolated volume as percentage of forced vital capacity; $V$ be: backward extrapolated volume; FET: forced expiratory time; $\triangle \mathrm{FVC}$ : absolute difference between two highest forced vital capacities; $\triangle F_{E V V}$ : absolute difference between two highest forced expiratory volumes in one second; $\triangle \mathrm{FVC} \%$ : percentage difference between two highest forced vital capacities; $\triangle F E V 1 \%$ : percentage difference between two highest forced expiratory volumes in one second.

the PFT laboratory. All children selected were experienced in performing MEFV measurements, i.e. they had previously performed MEFV manoeuvres on at least two earlier occasions. The children were optimally encouraged, and performed, after full inspiration, a maximally forced and prolonged expiration. According to the trained and experienced pulmonary function technicians, their MEFV manoeuvres were acceptable when the flow/volume curves showed: 1) a rapid rise to peak flow and 2) a full, maximally prolonged expiratory curve, shown by a gradual, asymptotic approach of the curve to the volume axis. If necessary, especially for the first MEFV tests in young children, a computerized visual incentive was used to stimulate this manoeuvre. This consisted of a peak flow-triggered series of burning candles on the computer screen [2]. All MEFV curves with a gradual rise to peak flow, with blunt peaks and/or with sudden end expiratory drop of flow to the volume axis, were not accepted for

Table 2. - Patient characteristics

Characteristics

Sex $M / F$

Age yrs

Weight $\mathrm{kg}$

Height $\mathrm{cm}$

FEV $1 \%$ pred

FVC $\%$ pred

FEV $1 \%$ FVC

Data are presented as mean \pm SD (range) unless otherwise stated. FEV1: forced expiratory volume in one second; FVC: forced vital capacity; FEV $1 \%$ FVC: FEV 1 as a percentage of FVC; M: male; F: female. further evaluation. All children performed at least three technician-accepted curves; and for each child, the two curves with the highest sum of forced vital capacity (FVC) and forced expiratory volume in one second (FEV1) during the last PFT were used for the final analysis [5].

Finally, 446 children (aged 5-19 yrs) who had performed MEFV manoeuvres on an average of 16.7 occasions could be evaluated. Patient characteristics are given in table 2 .

It was evaluated whether these technician-accepted curves met the ATS and ERS criteria [3, 4] for acceptability and reproducibility (table 1) using backward extrapolated volume ( $V$ be) as an absolute value and as a percentage of FVC ( $V \mathrm{be} \% \mathrm{FVC}$ ) (fig. 1) for the start-of-test and the forced expiratory time (FET) for the end-of-test. The best value of the two curves for each patient was used for evaluation of acceptability criteria. Reproducibility was evaluated by the absolute and percentage difference between FVCs $(\triangle \mathrm{FVC}$ and $\Delta \mathrm{FVC} \%$ ) and the absolute and percentage difference between FEV1 $(\triangle \mathrm{FEV} 1$ and $\triangle \mathrm{FEV} 1 \%)$ of the two best curves out of a minimum of three curves per individual.

Time to peak expiratory flow ( $t \mathrm{PEF}$ ) as the startof-test criterion, mentioned in earlier standardization reports [6] but not accepted in later consensus reports [3], was also analysed. All values of ATS and ERS criteria were also related to age, height, sex and pulmonary function results. In order to be able to propose new criteria, the authors calculated the values that could be achieved by $90 \%$ of the children studied.

\section{Statistical analysis}

Values (mean $\pm \mathrm{SD}$, range) were calculated for all criteria. Correlations between criterion values and age, height and pulmonary function were studied with Pearson's correlation coefficients.

Differences between separate groups were analysed using unpaired t-tests. A p-value $<0.05$ was considered statistically significant.

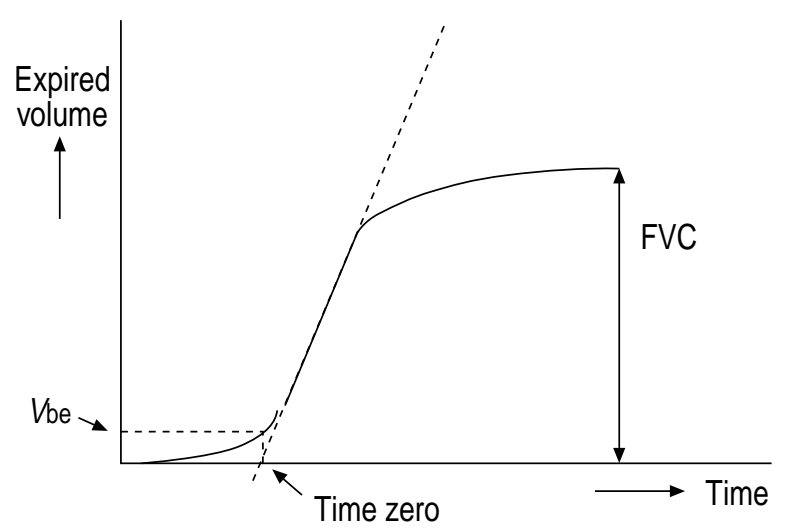

Fig. 1.- Schematic diagram of the method to determine the backward extrapolated volume ( $V$ be) from a volume/time curve. $V$ be should be $<5 \%$ of the forced vital capacity (FVC) to represent an acceptable start of forced expiration. 
Table 3. - Percentages of "technician-accepted" maximal expiratory flow/volume curves that meet the American Thoracic Society and/or European Respiratory Society acceptability and reproducibility criteria

\begin{tabular}{lccccc}
\hline Criterion & \multicolumn{4}{c}{ Age } & \multirow{2}{*}{ Total } \\
\cline { 2 - 5 } & $<8$ yrs & $8-11$ yrs & $12-15$ yrs & $>15$ yrs \\
\hline Patients n & 36 & 175 & 146 & 89 & 446 \\
$V_{\text {be } \% \text { FVC }<5 \%}$ & 77.2 & 80.6 & 91.7 & 96.5 & 91.5 \\
$V$ be $<0.15 \mathrm{~L}$ & 97.5 & 95.6 & 94.5 & 85.4 & 94.8 \\
$V_{\text {be }}<0.10 \mathrm{~L}$ & 77.8 & 61.7 & 59.6 & 50.6 & 60.1 \\
$t$ PEF $<0.1 \mathrm{~s}$ & 75.3 & 77.8 & 89.9 & 92.0 & 84.7 \\
FET $>6 \mathrm{~s}$ & 8.6 & 13.3 & 15.6 & 36.0 & 15.3 \\
$\Delta$ FVC $<200 \mathrm{~mL}$ & 100 & 99.5 & 94.5 & 95.5 & 97.1 \\
$\Delta$ FVC $<100 \mathrm{~mL}$ & 91.7 & 85.7 & 74.7 & 70.8 & 79.8 \\
$\Delta$ FVC $\%<5 \%$ & 82.7 & 89.8 & 85.6 & 89.5 & 87.9 \\
$\Delta$ FEV $1<200 \mathrm{~mL}$ & 100 & 99.0 & 98.2 & 97.5 & 98.4 \\
$\Delta$ FEV $1<100 \mathrm{~mL}$ & 91.7 & 90.9 & 78.1 & 79.8 & 84.3 \\
$\Delta$ FEV $1 \%<5 \%$ & 91.4 & 85.7 & 87.2 & 88.5 & 87.2 \\
\hline
\end{tabular}

Data are presented as percentages unless otherwise stated. $V$ be\%FVC: backward extrapolated volume as percentage of forced vital capacity; $V$ be: backward extrapolated volume; $t$ PEF: time to peak expiratory flow; FET: forced expiratory time; $\triangle \mathrm{FVC}$ : absolute difference between two highest forced vital capacities; $\triangle \mathrm{FVC} \%$ : percentage difference between two highest forced vital capacities; $\triangle F E V 1$ : absolute difference between two highest forced expiratory volumes in one second; $\triangle \mathrm{FEV}_{1} \%$ : percentage difference between two highest forced expiratory volumes in one second.

\section{Results}

Results for the different criteria are given in tables 3 and 4.

\section{Acceptability criteria: start-of-test}

Backward extrapolated volume as a percentage of forced vital capacity. The $V \mathrm{be} \% \mathrm{FVC}$ was $<5 \%$ in $91.5 \%$ of all patients. The mean best $V \mathrm{be} \% \mathrm{FVC}$ was $3.3 \pm 1.7 \%$ (range 0.7-9.5) (tables 3 and 4). The $V$ be $\% F V C$ was weakly, though significantly related to height, age and pulmonary function (table 4 ). The authors found that
$77.2 \%$ of children $<8$-yrs-old were able to reach this criterion (tables 3 and 4).

Backward extrapolated volume. The Vbe was $<0.15 \mathrm{~L}$ in $94.8 \%$ of the children. The mean best $V$ be was $0.09 \pm$ $0.03 \mathrm{~L}$ (range $0.04-0.24$ ). The $V$ be was significantly related to height and age (table 4).

Time to peak expiratory flow. A $t \mathrm{PEF}<0.10 \mathrm{~s}$ was seen in $84.7 \%$ of all children. Mean $t$ PEF was $0.07 \pm 0.03 \mathrm{~s}$ (range $0.01-0.22$ ). It was found that $t$ PEF was significantly inversely related to height and age, with better results in older children (tables 3 and 4).

\section{Acceptability criteria: end-of-test}

Forced expiratory time. During maximal stimulation, the maximal FET was $<6 \mathrm{~s}$ in $84.7 \%$ of all children. Mean FET was $4.3 \pm 2.5 \mathrm{~s}$ (range $0.5-18.7$ ). There was a significant relationship of FET with age and height, especially with parameters of airway patency (table 4).

\section{Reproducibility criteria}

Absolute difference between two highest forced vital capacities. $\triangle \mathrm{FVC}$ was $<200 \mathrm{~mL}$ in $97.1 \%$ of children. The mean $\Delta \mathrm{FVC}$ was $58 \pm 50 \mathrm{~mL}$ (range $0-280$ ). $\Delta \mathrm{FVC}$ was significantly related to age and height, but not to sex (table 4). All patients in the youngest age group and $95.5 \%$ in the oldest age group met this criterion (table 3).

Percentage difference between two highest forced vital capacities. $\triangle \mathrm{FVC} \%<5 \%$ as a criterion for reproducibility was met by $87.9 \%$ of children (table 3 ). Mean $\Delta \mathrm{FVC} \%$ was $2.3 \pm 2.1 \%$ (range $0-10.7$ ). In the older age group, a higher proportion of the children reached the criterion, but correlation with both height and age was not statistically significant. There was a weak, although significant correlation between pulmonary function and $\triangle \mathrm{FVC} \%$ (table 4 ).

Table 4. - Mean values (mean \pm SD (range)) of American Thoracic Society and European Respiratory Society acceptability and reproducibility criteria, sex differences and Pearson's correlation coefficients $(R)$ for age, height and pulmonary function

\begin{tabular}{lccccccc}
\hline Criterion & Mean \pm SD (range) & Age & Height & Sex & FEV1 \% pred & FVC \% pred & FEV1\%FVC \\
\hline$V$ be $\%$ FVC $\%$ & $3.3 \pm 1.7(0.7-9.5)$ & $-0.30^{* * *}$ & $-0.45^{* * *}$ & NS & $0.15^{* *}$ & $0.23^{* * *}$ & $0.14^{* *}$ \\
$V$ be L & $0.09 \pm 0.03(0.04-0.24)$ & $0.14^{* *}$ & $0.27^{* * *}$ & NS & NS & NS & NS \\
$t$ PEF s & $0.07 \pm 0.03(0.01-0.22)$ & $-0.28^{* * *}$ & $-0.28^{* * *}$ & NS & NS & NS & 0.17 \\
FET s & $4.3 \pm 2.5(0.5-18.7)$ & $0.30^{* * *}$ & $0.20^{* * *}$ & NS & $0.50^{* * *}$ & 0.20 & $0.72^{* * *}$ \\
$\Delta$ FVC mL & $58 \pm 50(0-280)$ & $0.19^{* * *}$ & $0.30^{* * *}$ & NS & NS & NS & $0.14^{* *}$ \\
$\Delta$ FVC $\%$ & $2.3 \pm 2.1(0-10.7)$ & NS & NS & NS & $0.29^{* * *}$ & $0.24^{* * *}$ & $0.19^{* * *}$ \\
$\Delta$ FEV $1 \mathrm{~mL}$ & $51 \pm 50(0-330)$ & $0.20^{* * *}$ & $0.28^{* * *}$ & NS & NS & SS & NS \\
$\Delta$ FEV $\%$ & $2.5 \pm 2.7(0-14.6)$ & NS & NS & NS & $0.31^{* * *}$ & $0.28^{* * *}$ & $0.18^{* * *}$ \\
\hline
\end{tabular}

FEV1: forced expiratory volume in one second; FVC: forced vital capacity; FEV1\%FVC: FEV1 as a percentage of FVC; $V$ be\%FVC: backward extrapolated volume as percentage of FVC; $V$ be: backward extrapolated volume; $t$ PEF: time to peak expiratory flow; FET: forced expiratory time; $\triangle \mathrm{FVC}$ : absolute difference between two highest FVCs; $\Delta \mathrm{FVC} \%$ : percentage difference between two highest FVCs; $\triangle F^{2} V_{1}$ : absolute difference between two highest FEV1; $\Delta \mathrm{FEV}_{1} \%$ : percentage difference between two highest $\mathrm{FEV} 1 ; \%$ pred: percentage of predicted value; NS: nonsignificant. $* *: p<0.01 ; * * *: p<0.001$. 
Absolute difference between two highest forced expiratory volumes in one second. $\Delta \mathrm{FEV} 1$ was $<200 \mathrm{~mL}$ in $98.4 \%$ of all children. All patients in the youngest age group and $97.5 \%$ in the oldest age group met this criterion (table 3 ). The mean $\triangle \mathrm{FEV} 1$ was $51 \pm 50 \mathrm{~mL}$ (range $0-330)$. The $\triangle \mathrm{FEV} 1$ was significantly related to age and height (table 4 ).

Percentage difference between two highest forced expiratory volumes in one second. $\Delta \mathrm{FEV} 1 \%$ was $<5 \%$ in $87.2 \%$ of the children (table 3 ). The mean $\triangle F V_{1} \%$ was $2.5 \pm 2.7 \%$ (range $0-14.6$ ) and there was no significant correlation with height or age; however, a weak, although significant correlation with pulmonary function was found (table 4).

\section{Feasibility}

Table 5 presents the values of the different criteria, achievable by $90 \%$ of the children. The end-of-test criterion of FET $>6 \mathrm{~s}$ is the least feasible, especially in the younger age group (table 3 ).

\section{Discussion}

The majority of the children studied could perform acceptable flow/volume manoeuvres according to the ATS and ERS start-of-test criteria; only a minority of the children exhaled as long as required by the ATS, notwithstanding, the curves were judged to have been acceptably performed. When the absolute difference in FVC or FEV1, as proposed by the ATS, was taken as a criterion of reproducibility, this was easily met by the majority of children. Despite these findings, most of the criteria showed dependency upon age and height, which precludes the applicability of these

Table 5. - Cut-off points for acceptability and reproducibility criteria for values which can be achieved by $90 \%$ of the study population

\begin{tabular}{|c|c|c|c|c|c|}
\hline \multirow[t]{2}{*}{ Criterion } & \multicolumn{4}{|c|}{ Age } & \multirow[t]{2}{*}{ Total } \\
\hline & $<8$ yrs & $8-11$ yrs & $12-15 \mathrm{yrs}$ & $>15$ yrs & \\
\hline Patients $\mathrm{n}$ & 36 & 175 & 146 & 89 & 446 \\
\hline$V \mathrm{be} \% \mathrm{FVC} \%$ & 6.4 & 5.8 & 4.6 & 4.2 & 5.4 \\
\hline$V$ be $\mathrm{L}$ & 0.11 & 0.12 & 0.12 & 0.16 & 0.13 \\
\hline$t \mathrm{PEF} \mathrm{S}$ & 0.11 & 0.12 & 0.10 & 0.09 & 0.11 \\
\hline FET s & 1.3 & 2.1 & 1.8 & 2.1 & 1.8 \\
\hline$\Delta \mathrm{FVC} \mathrm{mL}$ & 83 & 101 & 159 & 150 & 127 \\
\hline$\Delta \mathrm{FVC} \%$ & 5.0 & 4.9 & 5.6 & 4.7 & 5.3 \\
\hline$\Delta \mathrm{FEV} 1 \mathrm{~mL}$ & 60 & 92 & 128 & 136 & 110 \\
\hline$\Delta \mathrm{FEV}_{1} \%$ & 4.7 & 6.3 & 6.7 & 5.4 & 6.2 \\
\hline
\end{tabular}

Vbe\%FVC: backward extrapolated volume as percentage of forced vital capacity; $V$ be: backward extrapolated volume; $t$ PEF: time to peak expiratory flow; FET: forced expiratory time; $\triangle \mathrm{FVC}$ : absolute difference between two highest forced vital capacities; $\triangle \mathrm{FVC} \%$ : percentage difference between two highest forced vital capacities; $\triangle \mathrm{FEV} 1$ : absolute difference between two highest forced expiratory volumes in one second; $\triangle \mathrm{FEV} 1 \%$ : percentage difference between two highest forced expiratory volumes in one second. criteria for children of all ages. In children, absolute criteria are considered to be less suitable, especially when they are age-dependent and designed for adults. The focus should be on the applicability of relative criteria that are designed to control for changes in the absolute magnitudes of measurements with (pulmonary) growth.

Apart from growth, in childhood many other factors, such as the time and patience of the PFT technician, equipment, use of incentives and disease state, may influence the results of pulmonary function testing. To perform acceptable and reproducible MEFV manoeuvres, the child should be able to blow out forcefully, immediately after maximal inhalation, and to continue forced expiration until no further air can be expired. The instruction and control of technique, combined with sufficient patience, requires a well-trained PFT technician able to cope with and to encourage children and able to judge the expiratory process [7]. Several groups reported successful MEFV measurements in young children. KANENGISER and Dozor [8] reported that many 3-5-yr-old children are able to cooperate and perform rudimentary forced expiratory manoeuvres that are reproducible; however, reliability could not be assumed and few MEFV curves met the ATS criteria for acceptability. LE SoEuf et al. [9] found that children can perform adequate forced expiratory manoeuvres from the age of $4-5$ yrs.

The present study investigates the applicability of the current officially accepted reliability criteria, as defined by the ATS [3, 5] and the ERS working groups [4].

\section{Start-of-test criteria}

In young children, the initial efforts to produce a sharp peak flow are often not very rapid in onset. The present study shows that with the guidance of a welltrained technician, the majority of experienced children can reach the current start-of-test criteria.

In earlier reports on spirometry criteria, $t$ PEF was described as a start-of-test parameter [6]. If applied, a good start of the forced expiratory manoeuvre (i.e. $t$ PEF $<0.10 \mathrm{~s}$ ) was seen in $84.7 \%$ of children. For peak expiratory flow (PEF) meters, the use of dwell and rise time for PEF, recently described by MILLER et al. [10], needs further study and has not been used in MEFV manoeuvres in children. Their results showed that males and asthmatics, in particular, had shorter "start times" compared to females and nonasthmatics. In the present study, the percentage of children who reached a peak flow within $0.1 \mathrm{~s}$ was rather low compared to the current ATS and ERS start-of-test criteria, thus excluding MEFV measurements in a considerable number of children. Therefore, the present study supports the former recommendation that $t$ PEF should not be used as a criterion of acceptability.

The study indicates that the subjective criterion of a "rapid rise to peak flow", often estimated by eye by PFT technicians, is sufficient to select acceptable curves. Optimally, criteria for acceptability should be independent of age or height. However, the present data show that none of the ATS start-of-test criteria are independent of growth. Age and height are 
negatively correlated with $V \mathrm{be} \% \mathrm{FVC}$ and positively correlated with $V$ be. This can be explained by the rise in FVC during growth.

The parameter $V$ be, although an "absolute" parameter, is the most independent of age and height, and therefore, this parameter seems to be the most appropriate start-of-test criterion. The $V$ be $<0.15 \mathrm{~L}$ criterion was met by $>94.5 \%$ of children aged $<15$ yrs and $85.4 \%$ of children aged $\geqslant 15$ yrs (table 3 ). The ERS criterion of $V$ be $<0.10$ L excludes $\leqslant 50 \%$ of MEFV curves in older children. A minimal $V$ be of $0.12 \mathrm{~L}$ in children aged $<15$ yrs is advised; $90 \%$ of children would then be able to reach the acceptability standard (table 5).

\section{End-of-test criteria}

The second part of the MEFV manoeuvre was far more difficult to perform for children. The ATS criterion for acceptability demands an FET of $\geqslant 6 \mathrm{~s}$, unless there is an obvious plateau in the volume/ time curve display. The ATS recommendations state that shorter exhalation times are acceptable in children, but they fail to be more specific [3]. The ERS working group does not present numerical criteria for maximally prolonged expiration [4]. In this study, all children had extensive experience with lung function testing and were encouraged to reach complete exhalation. Nevertheless, only $36 \%$ of the eldest group in the study exhaled for $>6 \mathrm{~s}$. Although mean FET rises with age, even adolescents did not always exhale (forcefully) during $>6 \mathrm{~s}$, thereby making this criterion unsuitable for use in paediatric practice.

DESMOND et al. [11] found comparable results. In their study, an FET of $\geqslant 6$ s was reached by $28 \%$ and $7 \%$ of children over and under the age of $7 \mathrm{yrs}$, respectively. In contrast, a recent study by ENRIGHT et al. [12] showed that display of a real-time tracing of exhaled volume versus time, used to stimulate subjects and PFT technicians, allowed for higher FETs in children $>9$ yrs of age. However, start-of-test criteria were less easily reached, compared to the present study's group of children. These results show that the use of a particular device will enable more children to satisfy specific criteria, but probably not all criteria. In the present study, a complete expiration, rather than an exhalation time of $6 \mathrm{~s}$, was considered as the goal of MEFV measurement. The statement of ENRIGHT et al. [12], that underestimation of the FVC is not clinically very important when monitoring children with obstructive pulmonary disease, is endorsed. Therefore, when necessary, especially in inexperienced and young children, the use of computerized visual incentives (e.g. burning candles) that visually stimulate a rapid and forced start of maximal expiration, is recommended [2].

WARWICK [13] described that young children may empty their lungs within $1 \mathrm{~s}$ as a result of small lung volumes. This causes the FEV 1 to be equal to FVC and could reduce the usefulness of FEV1 and FEV1 as a percentage of FVC (FEV $1 \% \mathrm{FVC})$ as an index of airway obstruction. KANENGISER and Dozor [8] stated that for this age group, the forced expiratory volume in half a second (FEV0.5) could be more appropriate in the determination of airway obstruction.

As would be expected, the degree of airway obstruction was positively related to the FET. The correlation of FET with age was more evident than with height (table 4), which suggests that in addition to lung volume, ageing and, therefore, probably effort and cooperation influence FET. Although ENRIGHT et al. [12] found better results using specific stimulation, it may be questioned how many adults can reach this FET criterion during routine pulmonary function testing.

In the present study, time criteria were defined which were reached by $90 \%$ of children. Assuming that the flow/volume curve shows no abrupt termination of expiratory flow and/or the volume/time curve shows a plateau (table 5), it is proposed that the minimal FET should be decreased to $2 \mathrm{~s}$ for children $\geqslant 8 \mathrm{yrs}$ of age and to $1 \mathrm{~s}$ for children $<8 \mathrm{yrs}$ of age. Other researchers suggested taking $3 \mathrm{~s}$ [11] or $4 \mathrm{~s}$ [12] as goals for exhalation times. The present data show that when children reach an FET of $\geqslant 2 \mathrm{~s}$, this confirms a maximal effort in $>90 \%$ of children.

\section{Reproducibility}

In the present study, the children, especially the younger ones, had no problems in meeting the "absolute volume" criteria for reproducibility (table 3 ). This is to be expected because of their small lung volumes, but it does not guarantee reproducibility. Reproducibility criteria using absolute differences for both FVC and FEV1 are significantly influenced by age and height (table 4). Criteria using the relative difference as mentioned by the ERS [4] are not correlated with either age or height, and, therefore, seem to be more appropriate in paediatric practice. The 5\% difference criteria were reached by $87.9 \%$ and $87.2 \%$ of children for FVC and FEV1, respectively (table 3). Increasing these numbers to $90 \%$ would require a cut-off point of $5.3 \%$ for FVC and $6.2 \%$ for FEV1 (table 5). The current 5\% criteria seems to be more useful in childhood than the absolute criterion of either 100 or $200 \mathrm{~mL}$.

\section{Study situation}

It should be stressed that all children in the present study were experienced with MEFV manoeuvres. Most children underwent regular PFTs during visits to the outpatient clinic. The mean number of PFTs performed by the children before the study was rather high. This means that, for inexperienced children, several attempts may be necessary to reach the same skills and results. As it could be the start of a "pulmonary testing career" that may last for many decades in children with chronic respiratory symptoms, it is important for inexperienced children to become familiar with the procedure and especially to use their first laboratory visits to adapt to the situation and gain a positive experience from it. If the first "PFT battle" is lost, good compliance and performance may be lost in later visits. 


\section{Conclusion}

Even maximal expiratory flow/volume manoeuvres of experienced children do not reach the goals of all European Respiratory Society and American Thoracic Society criteria. However, most of their maximal expiratory flow/volume curves are useful for interpretation. Re-evaluation of international criteria for maximal expiratory flow/volume measurements in children is proposed. Based on evaluation of maximal expiratory flow/volume measurements in 446 experienced children, the minimum criteria required are as follows. Start-of-test: backward extrapolated volume $<0.12 \mathrm{~L}(<15 \mathrm{yrs})$ and $<0.15 \mathrm{~L}$ ( $>15 \mathrm{yrs})$; end-of-test: forced expiratory time $>2 \mathrm{~s} \quad(>8 \mathrm{yrs})$ and forced expiratory time $>1 \mathrm{~s}(<8 \mathrm{yrs})$, provided that complete exhalation with a gradual, asymptotic approach of the flow/volume curve to the volume axis is seen; and reproducibility: percentage difference between the two highest forced expiratory volumes in one second and percentage difference between the two highest forced vital capacities $<5 \%$.

\footnotetext{
Acknowledgements. The authors thank M.A.S. Diederik-Zwijnenburg, W. Baars-de Gier, M. Stehouwer-de Gooijer, J.W. Klein Nagelvoort, J.M. Tersmette and C.E. de Lange, pulmonary function technicians at the Dept of Paediatric Pulmonology, for their assistance and cooperation.
}

\section{References}

1. Tiffeneau R, Pinelli A. Air circulant et air captif dans 1'exploration de la function ventilatrice pulmonaire. Paris Med 1947; 37: 624-628.

2. Schweitzer RC, Brackel HJL, Baars-de Gier W, Diederik-Zwijnenburg MAS, van der Ent CK. Forced flow-volume curves in healthy children aged
4-6 years using a computerized visual incentive. Eur Respir J 1998; 12: Suppl. 28, 84s.

3. Medical Section of the American Lung Association. Standardization of spirometry, 1994 update. Am J Respir Crit Care Med 1995; 152: 1107-1136.

4. Quanjer PH, Tammeling GJ, Cotes JE, Pedersen OF, Peslin R, Jernault J-C. Lung volumes and forced ventilatory flows. Report Working Party. Standardization of lung function tests. Eur Respir $J$ 1993; 6: Suppl. 16, 5s-40s.

5. American Thoracic Society. Standardization of spirometry: 1987 update. Am Rev Respir Dis 1987; 136: 1286-1296.

6. Enright PL, Johnson LR, Connett JE, Voelker H, Buist AS. Spirometry in the Lung Health Study. 1. Methods and quality control. Am Rev Respir Dis 1991; 143: 1215-1223.

7. Castile RG. Pulmonary function testing in children. In: Chernick V, Boat TF, eds and Kendig EL, consulting ed. Kendig's Disorders of the Respiratory Tract in Children. 6th Edn. Philadelphia, W.B. Saunders Company, 1998; pp. 196-213.

8. Kanengiser S, Dozor A. Forced expiratory maneuvres in children aged 3-5 years. Pediatr Pulmonol 1994; 18: 144-149.

9. Le Soeuf P, Lafortune B, Landau L. Spirometric assessment of asthmatic children aged 2-6 years. Aust N Z J Med 1986; 16: 625.

10. Miller MJ, Pedersen OF, Quanjer PH. The rise and dwell time for peak expiratory flow in patients with and without airflow limitation. Am J Respir Crit Care Med 1998; 158: 23-27.

11. Desmond KJ, Allen PD, Demizio DL, Kovesi T, Coates AL. Redefining end of test (EOT) criteria for pulmonary function testing in children. Am $J$ Respir Crit Care Med 1997; 156: 542-545.

12. Enright PL, Linn WS, Avol EL, Margolis HG, Gong H, Peters JM. Quality of spirometry performance in children and adolescents. Chest 2000; 118: 665671.

13. Warwick WJ. Pulmonary function in healthy Minnesota children. Minn Med 1977; 60: 435-440. 